\title{
PERENCANAAN SISTEM PRESENSI GURU BERBASIS APLIKASI ANDROID DI SMPN 6 JEMBER
}

\author{
Joni Iskandar ${ }^{1}$ \\ ${ }^{1}$ IAIN Jember, Jl. Mataram No.1 Mangli Jember, Jawa Timur Indonesia \\ e-mail: jonit4janet@gmail.com
}

\begin{abstract}
ABSTRAK
Attendance is an important factor in the aspect of attendance in an agency. The presence of teachers greatly influences the teaching and learning process in schools every day. Attendance is one way to record teacher attendance. Based on the results of observations and interviews at school, the attendance process is still done manually signing on paper. The attendance reporting process is still being carried out by means of a recap in the form of reports. Hence, a presence application is needed to facilitate the attendance process and the reporting process without recapitulating data because the data has been stored in a google spreadsheet. This is very useful for minimizing the occurrence of cheating in doing attendance at school, easily monitoring attendance and recapping teacher attendance data.
\end{abstract}

Kata Kunci: attendance, teacher presence, android application

\begin{abstract}
ABSTRAK
Absensi merupakan faktor penting dalam aspek kehadiran dalam suatu instansi. Kahadiran guru sangat berpengaruh terhadap proses belajar mengajar di sekolah setiap harinya. Presensi merupakan salah satu untuk mencatat kehadiran guru. Berdasarkan hasil observasi dan wawancara di sekolah proses presensi masih di lakukan secara manual tanda tangan di atas kertas. Proses pelaporan presensi juga masih dilakukan dengan cara rekap delam bentuk laporan. Makan diperlukan aplikasi presensi untuk memudahkan proses presensi dan proses pelaporan tampa merekap data karena data sudah disimpan kedalam google spreadsheet. Hal ini sangat bermanfaat untuk meminimalisir terjadinya kecurangan dalam melakukan presensi di sekolah, mudah memonitoring kehadiran dan rekap data presensi guru.
\end{abstract}

Kata Kunci : absensi,presensi guru, aplikasi android

\section{PENDAHULUAN}

Pada dasarnya, pembelajaran merupakan interaksi antara guru dalam mengajar (teacing) dan siswa dalam belajar (learning) (Imron Fauzi, 2008:80). Dalam pembelajaran, tingkat kehadiran 
siswa sangat berpengaruh karena menjadi standar keberhasilan siswa dalam belajar. Sistem kehadiran dalam kelas biasa dikenal dengan presensi.

Presensi adalah suatu kegiatan pengambilan data guna mengetahui jumlah ketidak hadiran guru dalam sebuah instansi. Proses presensi merupakan suatu kegiatan yang di lakukan dalam akademik di sekolah untuk mengetahui keaktifan guru dan siswa di sekolah. Sistem yang berjalan saat ini masih menggunakan cara manual yaitu dengan cara melakukan tanda tangan dilembar kertas untuk proses absensi.

Namun dalam pelaksanannya, presensi dalam proses pelaporan ke Dinas Pendidikan masih dilakukan dengan mengirim laporan dalam media kertas. Maka dari itu sistem yang menggunakan presensi komputerisasi menggunakan presensi online berbasis android sangat di butuhkan untuk mengurangi penggunaan kertas dan hasil presensi akan di kirim menggunakan database dinas pendidikan dengan memanfaatkan google Sheet yang dikelola admin sekolah sehingga lebih mudah dalam memonitoring kehadiran guru.

Berdasarkan wawancara dan observasi dengan ibu Dhianatus Sholeha S.Pd_selaku admin di SMPN 6 Jember menunjukkan bahwa pengambilan data absensi ini dilakukan secara manual memiliki kekurangan, seperti data tidak valid ketika data yang masuk salah, hilang atau rusaknya data yang ada, serta kurang efesien dan efektif pada pengelolaan data. Berdasarkan permasahan tersebut maka penulis tertarik melakukan penelitian Perencanaan Sistem Presensi Guru Berbasis Aplikasi Android Menggunakan Kamera Foto Di Lingkungan Smpn 6 Jember.

Defini perencanaan menurut Albahra Bin ladjamudin (2013:51) menyebutkan bahwa perencanaan adalah kemampuan untuk membuat beberapa alternatif pemecahan masalah. Pengertian sistem menurut McLeod (2001:35), sistem adalah sekelompok elemen-elemen yang terintegrasi dengan tujuan yang sama untuk mencapai tujuan.

Perangkat handphone android yang dimiliki oleh guru-guru dapat di manfaatkan untuk meningkatkan performa sistem pencatatan absensi di SMPN 6 Jember. Penelitian ini bertujuan untuk merancang dan membangun aplikasi presensi pada platform android untuk menfasilitasi proses absensi guru di SMPN 6 Jember. Sistem absensi guru dapat di bangun sebagai sebuah aplikasi yang dapat berfungsi optimal untuk mengelola data kehadiran maupun ketidak hadiran guru setiap harinya. Dikarenakan prangkat handphone android sudah banyak digunakan oleh guru SMPN 6 jember. Sehingga proses presensi menggunakan aplikasi android lebih efektif.

\section{METODE}

Mekanisme perencanaan penyusunan presensi berbasis android mengunakan metode penelitian Research and Development ( $\mathrm{R} \& \mathrm{D}$ ) dengan mengacu pada suatu penemuan dan pengembangan suatu produk. Sehingga diperlukan adanya uji efektif dam kebutuhan masyarakat terhadap produk 
tersebut. Dalam hal ini objek penelitian menggunakan aplikasi android dalam penggunaan absensi guru dan siswa berbasis online di SMP 6 Jember.

Langkah-langkah penelitian metode ini diantaranya: 1) menemukan potensi dan masalah;2) pengumpulan data; 3) Desain Produk; 4) Validasi Desain; 5) revisi desain; 6) uji coba produk; 7) Revisi Desain; 8) revisi produk; 9) produksi masal

\section{HASIL DAN PEMBAHASAN}

Hasil dari penilitia ini adalah Aplikasi Presensi Pada Platform Android. Komponen pendukung pada aplikasi ini adaalah google sheet yang di gunakan sebai tempat peyimpanan data presensi guru. Namun sebelum mengoperasikan aplikasi tersebut, maka harus diketahui terlebih dahulu pedoman bagi pengguna yang akan mengaksesnya, diantaranya:

Perencanaan pengembangan aplikasi presensi ini melalui beberapa tahapan Waterfall, yaitu :

\section{Requirement Analysis and Definition}

Tahap ini adalah tahap menganalisis kebutuhan yang di perlukan dalam pembuatan aplikasi absensi untuk SMPN 6 jember. Pada tahap ini dianalisis fitur-fitur yang akan di bangun dalam aplikasi presensi, seperti yang di tunjukkan oleh gambar 1 dan gambar 2.

Gambar 1 menunjukan proses alur pengimputan data seluruh nama guru.

1. User Mengakses Aplikasi Presensi.

2. User mengimput data guru SMPN 6 Jember.

3. User membuat tabel kehadiran

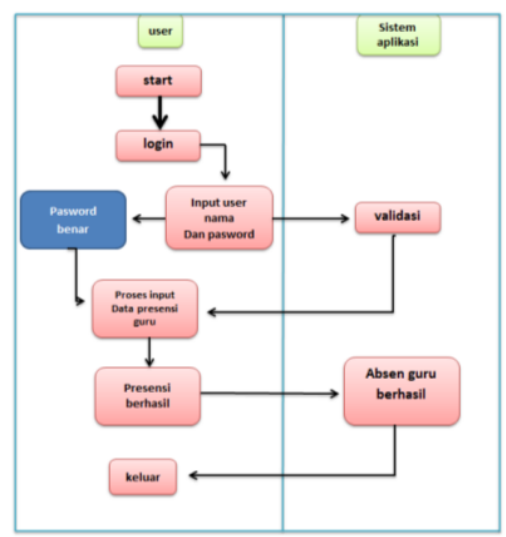

Gambar 1. Flowchart Sistem pada aplikasi 


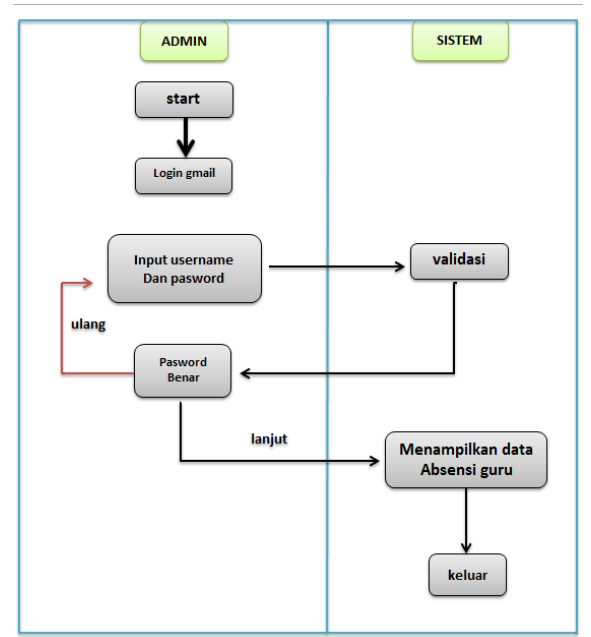

Gambar 2. Flowchart sistem untuk menampilkan data absensi yang telah tersimpan

Gambar 2 menunjukan alur proses sistem untuk menampilkan rekapitulasi data absensi guru yang disimpan oleh Aplikasi Absensi pada Google Drive pada akun Google milik admin.. Tahapan untuk mengakses rekapitulasi kehadiran guru adalah seperti berikut:

1. User mengakses Gmail gogle drive.

2. User mengimput kayword berupa gmail dan password gmail untuk melihat kehadiran guru berupa data excel yang berada di google driver yang menampilkan data kehadiran guru.

\section{Sistem and software design}

Pada tahapan ini proses desain untuk tampilan aplikasi presensi yang meliputi desain sistem aplikasi. Tahapan ini menghasilkan beberapa data kehadiran,foto guru dan diagram kehadiran.kemudian pada tahapan ini juga di hasilkan desaign interface dalam bentuk stroyboard.

1. Use Case diagram, mempresentasikan interaksi antara user dengan sistem pada aplikasi presensi.

Gambar 3. Menunjukkan interaksi User pada sistem aplikasi ini terjadi proses login, absensi, foto, lihat kehadiran guru, diagram kehadiran dan logout.

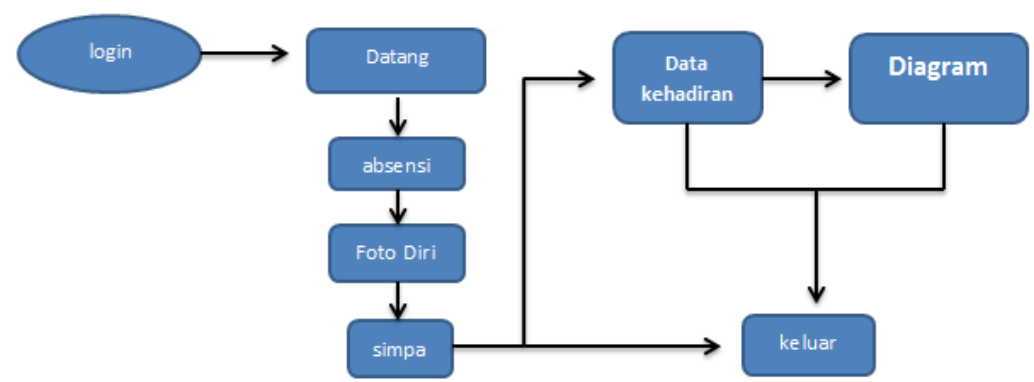

Gambar 3. Use Case Diagram Tampilan aplikasi presensi 


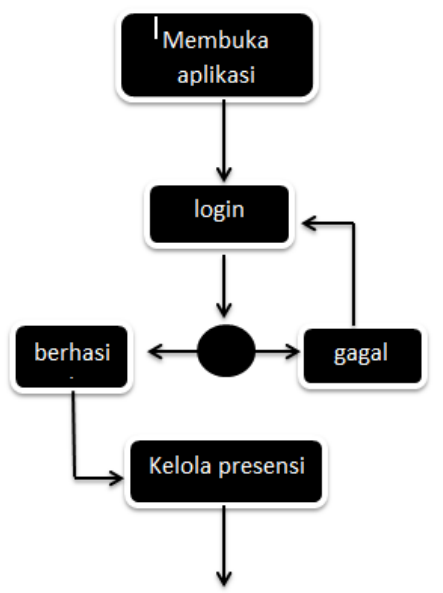

Gambar 4. Activity diagram pengisian data presensi user dan guru

2. Activity diagram. Menggambarkan alur kegiatan di dalam sistem aplikasi presensi.

Gambar 4 menunjukkan activity diagram bagi user dan guru saat melakukan pengisian data presensi. Aliran aktifitas di mulai saat membuka aplikasi mengisi absensi,foto,dan logout dari sistem aplikasi.

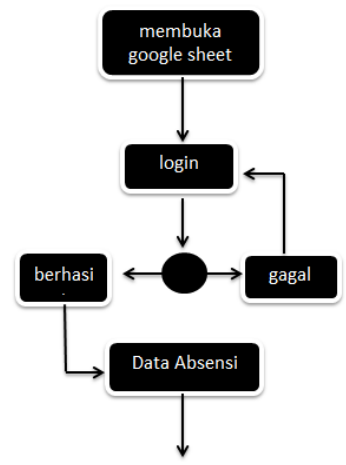

Gambar 5. Class Diagram untuk melihat data guru

3. Class Diagram, menggambarkan struktur dan deskripsi class package dan objek beserta hubungan objek-objek dalam aplikasi presensi. Gambar 5 menunjukkan class diagram Aplikasi presensi dan data guru.

4. Storyboard, merupakan gambaran dari Aplikasi Presensi di buat berdasarkan kebutuhan sekolah SMPN 6 Jember sebagai rekomendasi untuk menyempurnakan tampilan dalam menangani interaksi antara user dan sistem pada aplikasi presensi. Gambar 6 menunjukkan scane form logi aplikasi presensi. Gambar 7. Menampilkan data guru SMPN6 Jember. 


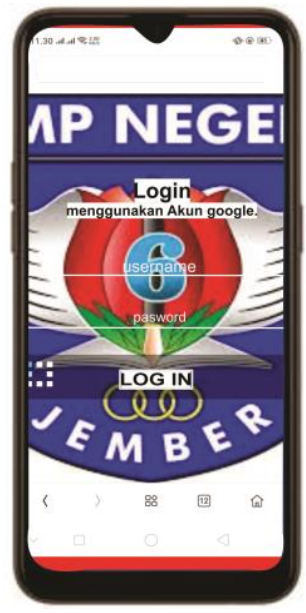

Gambar 5. Form login

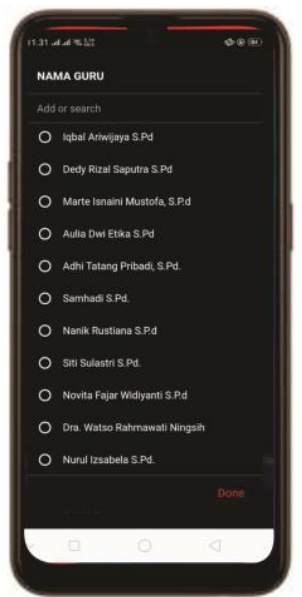

Gambar 6. Daftar nama guru

A. Implementation and unit testing, pada tahapan implementation and unit testing dilakukan proses pembuatan aplikasi presensi yaitu proses pengimputan data guru dan pengkodingan hingga menghasilkan satu unit program. Tahap ini merupakan implementasi dari tahap desain.

B. Integration and system testing,pada tahapan Integration and system testing, setiap fitur dalam aplikasi presensi diintegrasikan dan diuji sebagai satu sistem yang untuh untuk memastikan sistem sudah memenuhi persyaratan yang ada. Setelah ini sistem akan di kirim kepada pengguna sistem yaitu pihak sekolah. Testing yang di gunakan dalam penelitian ini adalah blackbox testing.

C. Operation and maintenance

Pada tahapan operation and maintenance, aplikasi absensi siap untuk instansi dan mulai di gunakan sebagai mana fungsinya. Pada tahap ini juga dilakukan perbaikan terhadap kesalahan yang tidak ditemukan pada proses pengkodean sebelum menjadi program utuh. Dalam tahap ini juga dilakukan pengembangan sistem seperti penambahan fitur dan logo sekolah sekolah SMPN 6 Jember.

Gambar 7 adalah pengisian data absensi yang ditampilkan setelah guru berhasil login. Untuk proses absensi setelah guru berhasil login guru dapat mengisi nama, keteranga (Hadir, Ijin, Sakit dan Alpa.) setelah guru selesai mengisi absensi dan menekan tombol save. Maka data akan terkirim ke google sheet dari akun google user. Gambar 8 menampilkan gambar hasil kehadiran guru dan foto guru seperti yang di aplikasikan langsung oleh guru SMPN 6 jember yaitu bapak Wardoyo S.E. Gambar 9. Adalah data diagram kehadiran keseluruhan berbentuk persentase. 


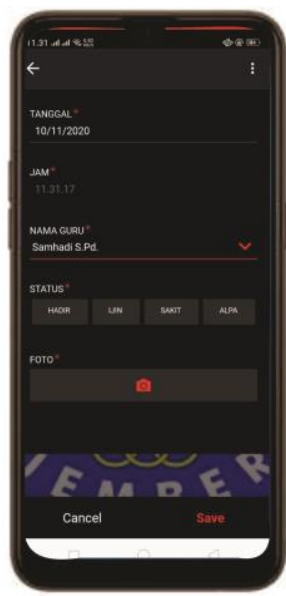

Gambar 7. Pengisian kehadiran
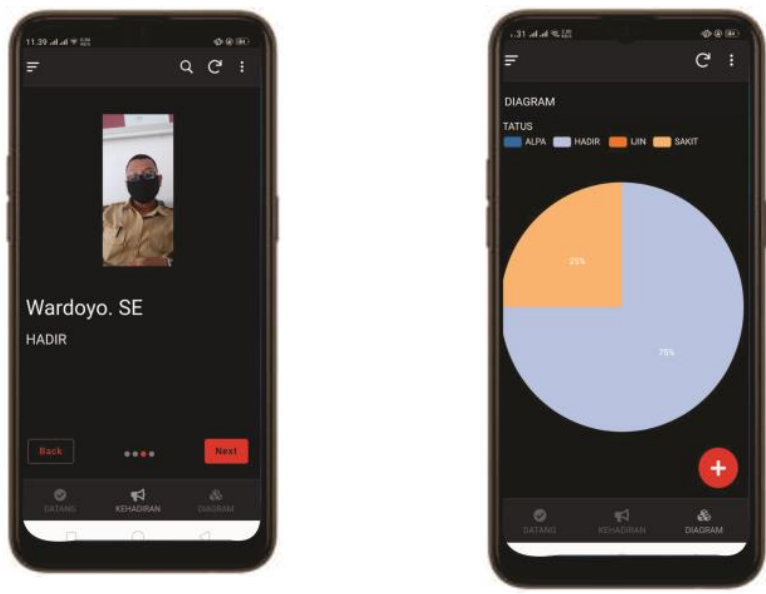

Gambar 8. Hasil foto aplikasi Gambar 9. Data diagram kehadiran

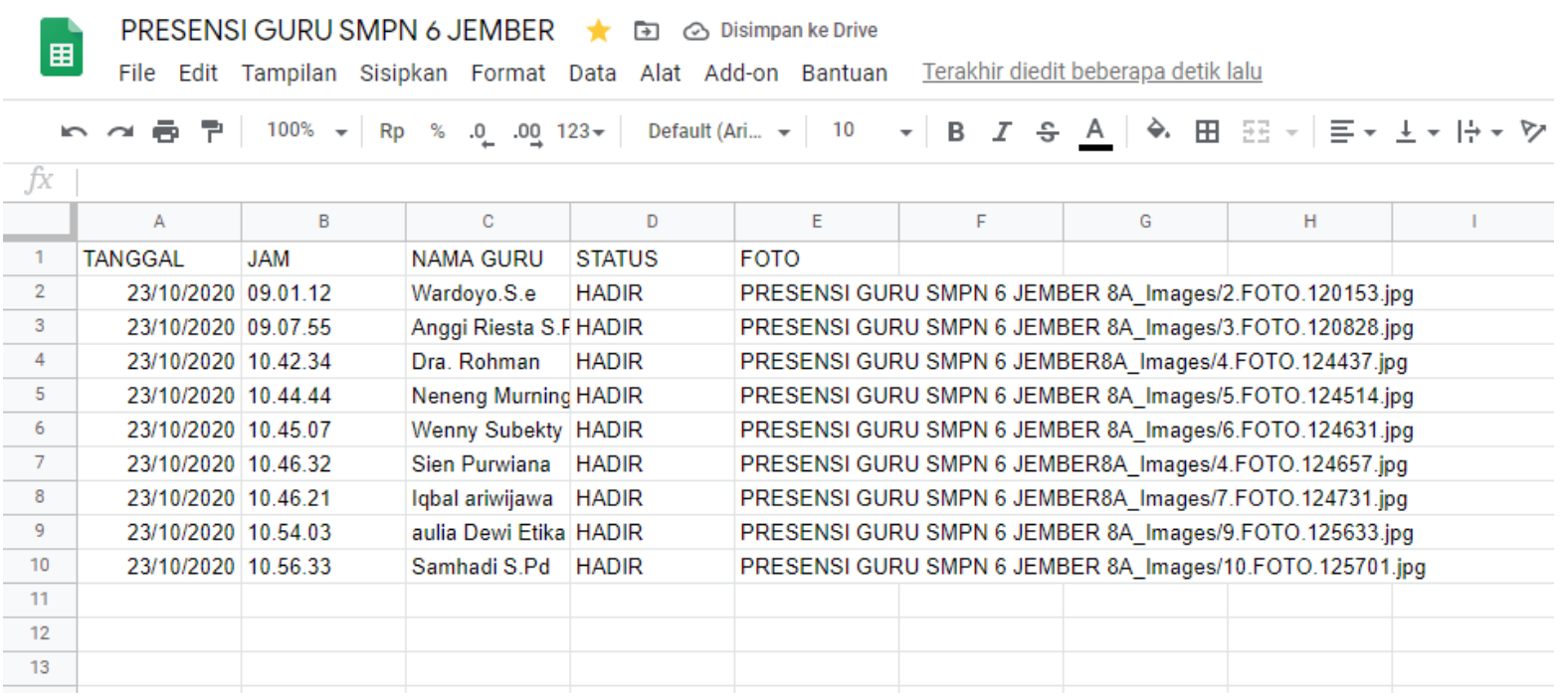

Gambar 10. Table kehadiran presensi yang dilakukan langsung oleh guru SMPN 6 Jember

Pengujian sistem dilakukan dengan blackbox testing untuk membuktikan bahwa aplikasi Presensi dapat berfungsi sesuai tujuan. Hasil pengujian dapat di lihat pada gambar 10. Pengujian yang langsung kepada guru SMPN 6 jember. Data kehadiran beserta foto yang dikirim langsung ke google sheet .

Memiliki sistem yang baik unntuk menngelola data kehadiran guru adalah tujuan dari semua sekolah untuk meningkatkan mutu pendidikan dan memberi perlayan terbaik bagi guru,siswa dan orang tua dan semua pihak yang bersangkutan. Oleh karena itu banyak penelitian tulah dilakukan untuk memenuhi kebutuhan sekolah dalam pengelolaan data dan informasi terkait kehadiran guru dalah kegiatan mengajar di sekolah. 
Moh. Lukman Sholeh dan Lutfi Ali Muharrom S,Si. M,Si. telah mambangun sistem presensi mahasiswa menggunakan QR code yang teritegrasi dengan sistem akademik universitas muhammaddiyah jember berbasis android. Sistem yang dibangun oleh moh lukman sholeh. Hanya digunakan untuk presensi ketika UTS dan Uas.

Aplikasi Presensi yang di buat pada penelitian ini lebih simpel di banding penelitian yang di bandingkan dengan Moh. Lukman sholeh dan lutfi ali muharrom S,Si. M,Si. sistem pada penelitian ini di bangun pada platform android. Kemudia data kehadiran yang di kelola oleh google Sheet yang akunnya di kelola oleh user admin SMPN 6 Jember. Namun mengingat kebutuhan yang besar dan berangam tentang informasi kehadiran yang lebih akurat. fungsi dan penyimpanan pada aplikasi presensi ini masih harus di kembangkan lagi sesuai dengan kebutuhan sekolah dan pihak-pihak yang berkepentingan.

\section{KESIMPULAN DAN SARAN}

Pesensi ini di bangun dengan menggunakan metode perangkat lunak waterfall. Data presensi pada aplikasi ini akan di simpan otomatis kedalam sistem Google sheet. Hasil pengujian pada aplikasi presensi ini menunjukkan bahwa aplikasi dapat berjalan sesuai tujuan yang diinginkan. Saran bagi penelitian selanjutnya agar memperbaiki penyimpanan sistem yang di kelola pada Google sheet agar lebih optimah sesuai kebutuhan sekolah.

\section{DAFTAR PUSTAKA}

Abdul Kadir. 2002. Pemrograman Web HTML, CSS, Javascript, dan PHP. Andi. Yogyakarta.

Al-Bahra Bin Ladjamudin. 2013. Analisis dan Desain Sistem Informasi. Graha Ilmu. Yogyakarta. Fauzi Imron, Etika Profesi Keguruan, IAIN Jember press

Moh. Lukman Sholeh Dan Lutfi Ali Muharrom S,Si. M,Si 2016 (Smart Presensi Menggunakan QrCode Dengan Enkripsi Vigenere Cipher(J.Math and Its App),13 (2),31-44. Jember, Limity Shaweddy, Vidi Valianto (2011) Pembangunan Sistem Informasi Absensi Dengan Input Fingerprint Dan Barcode Berbasis Web Dan Sms Pada Proses Belajar Mengajar. S1 Thesis, Uajy. 